\title{
ASSOCIATION OF HYPERTENSION AND CORONARY HEART DISEASE WITH STROKE: A HOSPITAL BASED CASE CONTROL STUDY FROM KISHANGANJ, BIHAR
}

\author{
Anuj Kumar Saha1, Kashif Shahnawaz ${ }^{2}$ \\ ${ }^{1}$ Associate Professor, Department of Medicine, MGM Medical College \& LSK Hospital, Kishanganj, Bihar. \\ ${ }^{2}$ Assistant Professor, Department of Community Medicine, MGM Medical College \& LSK Hospital, Kishanganj, Bihar.
}

\begin{abstract}
Stroke is a major cause of mortality and morbidity worldwide and commonly occurs amongst elderly. Every year, 15 million people worldwide suffer from stroke. Hypertension is the most powerful and important modifiable risk factor for all stroke subtypes. Approximately 30-40\% stroke risk reduction can be achieved with lowering of blood pressure only. Heart disease is also a strong risk factor for stroke, although only for one type of stroke, ischemic strokes.
\end{abstract}

\section{MATERIALS AND METHODS}

This was a retrospective, cross-sectional, case-control study conducted from Jan-2015 to March-2015 (3 months). Study was done among stroke patients aged 20 years and above, hospitalized in M.G.M Medical College and L.S.K Hospital, Kishanganj. Age and gender matched control subjects were selected among neurologically healthy people who were admitted for other ailments in this hospital. Sample size was 312 people, containing 156 cases and 156 controls. Statistical analysis was done using Med Calc Version 12.7.5.0 software. Chi-square test was used as test of significance and p value less than 0.05 was considered as significant.

\section{OBSERVATION}

Male:Female ratio among the cases and control was 1.51:1. Mean age of cases and controls were $51.30 \pm 11.13$ and $51.93 \pm 14.60$. Out of 156 cases, 97 (62.18\%) cases were having history of hypertension, while only $33(21.15 \%)$ controls had hypertension. P value was 0.0001 , which is significant. Coronary heart disease was present in 21 (13.46\%) of cases and 6 (3.85\%) of controls. P value was significant.

\section{CONCLUSION}

To conclude in the present hospital-based case control study, systemic hypertension $(p<0.001)$ and coronary heart diseases were significant risk factors in patients with stroke. Thus, our present study is a step towards determination of risk factors of stroke.

\section{KEYWORDS}

Stroke, Hypertension, Coronary Heart Disease.

HOW TO CITE THIS ARTICLE: Saha AK, Shahnawaz K. Association of hypertension and coronary heart disease with stroke: a hospital based case control study from Kishanganj, Bihar. J. Evolution Med. Dent. Sci. 016;5(46):2865-2869, D0I: 10.14260/jemds/2016/668

\section{INTRODUCTION}

Stroke is a heterogeneous syndrome caused by many disease mechanisms, all of which result in disruption of cerebral blood flow and subsequent tissue damage. It is the second leading cause of death and one of the commonest causes of disability in adults. Hippocrates (460-370 BC) was first to describe stroke as "the phenomenon of sudden paralysis that is often associated with ischaemia." WHO. ${ }^{1}$ defines stroke as "neurological deficit of cerebrovascular cause that persists beyond $24 \mathrm{hrs}$. or is interrupted by death within $24 \mathrm{hrs."}$ As a result the affected area of brain is unable to function, leading to inability to move one or more limbs on one side of body, numbness, altered smell, taste, hearing, vision (Total or partial).

Stroke is a major cause of mortality and morbidity worldwide and commonly occurs amongst elderly. Every year, 15 million people worldwide suffer from stroke. Nearly six million die and another five million are left permanently

Financial or Other, Competing Interest: None.

Submission 18-04-2016, Peer Review 18-05-2016,

Acceptance 24-05-2016, Published 07-06-2016.

Corresponding Author:

Dr. Kashif Shahnawaz,

Manhar Road,

Chhoti Quazipura

Dist-Darbhanga-846004,

Bihar.

E-mail: kashif.shahnawaz98@gmail.com

DOI: $10.14260 /$ jemds/2016/668 disabled. From the last three decades, stroke remains the second most common cause of mortality.2, and recently has become the third leading cause of global disease burden estimated using disability adjusted life years. ${ }^{3}$ Disability due to stroke may include loss of vision and/or speech, paralysis and confusion. Globally, stroke is the second leading cause of death above the age of 60 years and the fifth leading cause of death in people aged 15-59 years old. ${ }^{4}$ Stroke is less common in people under 40 years, although it does happen.

In young people, the most common causes are high blood pressure or sickle cell disease. In developed countries, despite decreased incidence of stroke, paradoxically the absolute number of stroke victim still raises because of rapid ageing of population and tight correlation of stroke risk with age. ${ }^{5}$ These trends are accompanied by a decline of the mean age of stroke victims, which is now 69 years. ${ }^{6}$ In the developing world, however, the incidence of stroke is increasing. In China, 1.3 million people have a stroke each year and $75 \%$ live with varying degrees of disability as a result of stroke. Incidence of stroke ranges from 182-342 per 100,000 population in Asia. ${ }^{7}$ Indian population is relatively young [Indian population $\geq 60$ years: $7.5 \%$ compared to the west, but the stroke in India has already attained epidemic proportions [annual incidence of stroke: 13 per 100,000 in $1969-70$ and 145 per 100,000 per year during 2003-05 and 2005-06.8 In India, prevalence rate of stroke is 1.54 with a death rate of 0.6 per 1000 population. ${ }^{8}$ Real morbidity and mortality estimates for strokes in India are limited due to incomplete death certification, incorrect death classification and uncertainty of aetiology in cases of sudden 
death or multiple co-morbidities. Stroke may arise in different clinical situations with different aetiologies, epidemiological background and prognosis.

Stroke is a preventable disease. Hypertension is the most powerful and important modifiable risk factor for all stroke sub-types.9,10 and also have been found to be significantly associated with ischaemic stroke.11 It is not only the major risk factor for primary stroke, but it also increases the risk of cardiovascular morbidity and mortality and recurrent strokes in patients after stroke. The Indian Council of Medical Research (ICMR) has reported that 16\% ischaemic heart disease, 21\% peripheral vascular disease and 24\% Acute Myocardial Infarction (AMI), cases are attributed to hypertension. The Population Attributable Risk due to hypertension is $29 \%$ for stroke. ${ }^{12}$ Hypertension is responsible for $57 \%$ of all stroke deaths and $24 \%$ of all coronary heart disease deaths in India. ${ }^{13}$ Approximately, 30-40\% stroke risk reduction can be achieved with lowering of blood pressure only. Heart disease is also a strong risk factor for stroke, although only for one type of stroke, ischaemic strokes. ${ }^{14}$ Data from India on stroke among the young are mostly limited to ischaemic strokes. ${ }^{15}$ Studies have found a link between high blood lipid levels and atherosclerosis in cerebral arteries, but it is still unclear whether high cholesterol levels significantly increase stroke risk. They do, however, increase heart disease risk.16,17, so efforts should be made to reduce them. The risk of stroke rises significantly with age. After 55, it more than doubles with each passing decade. ${ }^{18}$

There are many other risk factors also which influence stroke risk, although to a lesser extent. These include an elevated haematocrit, geographic location, lower socioeconomic status, Type-A personality, use of cocaine and amphetamines and high alcohol consumption. Stroke deaths seem to occur more often during periods of extreme heat or cold. The risk factors for stroke vary internationally. Its risk factor profile may differ in different population groups. Detailed assessment of its underlying risk factors in stroke population of a country is relevant to understanding aetiology and planning preventive strategies to reduce future stroke burden.

The objective of our present study is to know an association of systemic hypertension and coronary heart disease with stroke in order to formulate strategy for its prevention.

\section{MATERIALS AND METHODS}

The present study was carried out in the Department of Medicine, Mata Gujri Memorial Medical College and Lions Seva Kendra Hospital (MGMMC and LSKH), Kishanganj, Bihar, a tertiary care centre of Kishanganj district, to study an association of systemic hypertension and coronary heart disease with stroke. Duration of the study was from Jan-2015 to March-2015 (3 months). This study was approved by Ethical Committee of MGMMC and LSK Hospital, Kishanganj. All the in-patients diagnosed with stroke, controls and their attendants attending this hospital during study period were explained the purpose of study and were invited to participate. Ethical aspects were explained and informed consent was obtained before enrolling them in study.

\section{STUDY DESIGN}

Type of Study

Retrospective, case-control study.

\section{Study Population}

Stroke patients aged 20 years and above hospitalized in M.G.M Medical College and L.S.K Hospital, Kishanganj. Age and gender matched control subjects were selected among neurologically healthy people who were admitted for other ailments in this hospital. The control subjects had no prior strokes or any neurological problem/deficit.

\section{Study Duration}

From Jan-2015 to March-2015 (3 months).

\section{Sample Size}

A total of 358 study subjects (179 cases and 179 controls) were included in the study, of which 23 cases could not participate and were drop-outs. To maintain case-control ratio (1:1), 23 controls were excluded from the study. The final sample size was 312 people, containing 156 cases and 156 controls.

\section{CASE DESCRIPTION \\ Case Definition}

WHO defines stroke as "neurological deficit of cerebrovascular cause that persists beyond 24 hrs. or is interrupted by death within $24 \mathrm{hrs}$. As a result, the affected area of brain is unable to function, leading to inability to move one or more limbs on one side of the body, numbness, altered smell, taste, hearing, vision (Total or partial). ${ }^{1}$

\section{Inclusion Criteria}

All patients of either sex aged 20 years and above who has stroke verified by CT scan of brain admitted in medicine ward of M.G.M. Medical College and L.S.K Hospital, Kishanganj.

\section{Exclusion Criteria}

The following patients were excluded from this study that had Subarachnoid haemorrhage, Transient Ischaemic attack, Syncopal attack, Presumptive diagnosis of stroke with equivocal neurological deficits but no lesion on CT scan brain, Neurological deficits secondary to epilepsy or head injury or an infective, metastatic aetiology, Pre-existing severe physical or cognitive disability, Trigeminal neuralgia.

\section{Data Collection}

Study participants were interviewed using a structured interview schedule. Proper training of staff nurses and interns was done for their co-operation in obtaining history of the study subjects about systemic hypertension and coronary heart disease. Subjects were classified as hypertensive if the mean blood pressure was $140 / 90 \mathrm{mmHg}$ or more in two different settings in supine position or there was a selfreported history of hypertension or history of receiving antihypertensive medications. Subjects were said to have coronary heart disease if there was present or past history of angina or the ECG showed ischaemic changes (Q-wave, ST segment or T-wave changes). Help and co-ordination were solicited from the attendants of the patients to complete the schedule as and when needed. Contact number and address of the patients were obtained and a visit was made to their family as far as possible. Patient's spouse or members of the family were interviewed to cross check the data obtained at their family setting.

\section{Statistical Analysis}

The data was analysed using Med Calc Version 12.7.5.0 software. Chi-square test was used as test of significance and 
$\mathrm{p}$ value less than 0.05 was considered as significant. Multivariate analysis was also carried out.

\section{OBSERVATIONS}

In our present study, Table 1 shows that in the age group 2039 years, there were 13 cases and 13 controls. In age group 40 59 years, there were 61 cases and 61 controls. There were 82 cases and 82 controls in the age group of $>60$ years. In Cases, $60.26 \%(n=94)$ were males and $39.74 \%(n=62)$ were females. In Controls, $60.26 \%(n=94)$ were males and $39.74 \%(n=62)$ were females. Male:Female ratio among the cases and control was 1.51:1. Mean age of cases and controls were $51.30 \pm 11.13$ and $51.93 \pm 14.60$. Ninety seven $(62.18 \%)$ cases out of 156 had history of hypertension, while only $33(21.15 \%)$ controls had hypertension. $\mathrm{P}$ value was 0.0001 , which is significant. [ $\mathrm{n}=312$ $\mathrm{OR}=6.12 ; \quad \mathrm{CI}=3.70-10.12 ; \mathrm{x}^{2}=53.84 ; \mathrm{p}=0.0001$ ] [Table-2]. Coronary heart disease was present in $21(13.46 \%)$ of cases and $6(3.85 \%)$ of controls. $P$ value was significant. $[n=312$; $\left.\mathrm{OR}=2.33 ; \mathrm{CI}=1.46-3.71 ; \mathrm{x}^{2}=12.85 ; \mathrm{p}=0.0003\right]$ [Table-3].

\begin{tabular}{|c|c|c|c|c|}
\hline $\begin{array}{c}\text { Age } \\
\text { Group }\end{array}$ & Cases & & Controls & \\
\hline & $\begin{array}{c}\text { Male } \\
(n=94)\end{array}$ & $\begin{array}{l}\text { Female } \\
(n=62)\end{array}$ & $\begin{array}{c}\text { Male } \\
(n=94)\end{array}$ & $\begin{array}{l}\text { Female } \\
(n=62)\end{array}$ \\
\hline $\begin{array}{c}20-39 \\
\text { yrs. }\end{array}$ & 9 & 4 & 9 & 4 \\
\hline $\begin{array}{c}40-59 \\
\text { yrs. }\end{array}$ & 38 & 23 & 38 & 23 \\
\hline $\begin{array}{l}>60 \\
\text { yrs. }\end{array}$ & 47 & 35 & 47 & 35 \\
\hline Total & 94 & 62 & 94 & 62 \\
\hline & 156 & & 156 & \\
\hline $\begin{array}{c}\text { Mean } \pm \\
\text { SD }\end{array}$ & $\begin{array}{c}51.30 \pm \\
11.13\end{array}$ & & $\begin{array}{c}51.93 \pm \\
14.60\end{array}$ & \\
\hline
\end{tabular}

\begin{tabular}{|c|c|c|c|}
\hline Hypertension & Cases & Controls & $\begin{array}{c}\mathbf{p} \\
\text { value }\end{array}$ \\
\hline Present & $\begin{array}{c}97 \\
(62.18 \%)\end{array}$ & $\begin{array}{c}33 \\
(21.15 \%)\end{array}$ & $\begin{array}{c}\mathrm{P}= \\
0.0001\end{array}$ \\
\hline \multirow{2}{*}{ Absent } & $\begin{array}{c}59 \\
(37.82 \%)\end{array}$ & $\begin{array}{c}123 \\
(78.85 \%)\end{array}$ \\
\hline \multirow{2}{*}{ Total } & $\begin{array}{c}\mathbf{1 5 6} \\
(\mathbf{1 0 0} \%)\end{array}$ & $\begin{array}{c}\mathbf{1 5 6} \\
(\mathbf{1 0 0} \%)\end{array}$ \\
\hline \multicolumn{3}{|c|}{ Table 2: Showing Hypertension } \\
among Cases and Controls \\
\hline
\end{tabular}

$\mathrm{n}=312 ; \mathrm{OR}=6.12 ; \mathrm{CI}=3.70-10.12 ; \mathrm{x}^{2}=53.84 ; \mathrm{p}=0.0001$.

\begin{tabular}{|c|c|c|c|}
\hline $\begin{array}{c}\text { Coronary Heart } \\
\text { Disease }\end{array}$ & Cases & Controls & p value \\
\hline Present & $\begin{array}{c}21 \\
(13.46 \%)\end{array}$ & $\begin{array}{c}06 \\
(3.85 \%)\end{array}$ & $\begin{array}{c}\mathrm{P}= \\
0.0003\end{array}$ \\
\hline Absent & $\begin{array}{c}135 \\
(86.54 \%)\end{array}$ & $\begin{array}{c}150 \\
(96.15 \%)\end{array}$ & \\
\hline Total & $\begin{array}{c}\mathbf{1 5 6} \\
(\mathbf{1 0 0} \%)\end{array}$ & $\begin{array}{c}\mathbf{1 5 6} \\
(\mathbf{1 0 0} \%)\end{array}$ & \\
\hline \multicolumn{4}{|c|}{ Table 3: Showing Coronary Heart Disease } \\
among Cases and Controls
\end{tabular}

$\mathrm{n}=312 ; \mathrm{OR}=2.33 ; \mathrm{CI}=1.46-3.71 ; \mathrm{x}^{2}=12.85 ; \mathrm{p}=0.0003$.

\section{DISCUSSION}

Stroke is a common clinical problem. Current treatment for patients with established stroke is relatively ineffective. Approximately, $50 \%$ of patients are left with permanent disability. Effective stroke factor intervention offers a real hope of reducing stroke morbidity and mortality. Certain risk factors have been consistently identified as significant predictor of stroke volume, while some are less consistent.

Consistent with the findings of other studies, this study showed that hypertension and coronary heart diseases have strong correlation and association with stroke and are the major risk factors of stroke.

A large case-control study evaluating risk factors for stroke was conducted in Beijing China, has shown that 10 risk factors are associated with $90 \%$ of the risk of stroke and of these modifiable risk factors hypertension is the most important for all stroke sub-types and is a particularly dangerous risk factor for intracerebral haemorrhage. ${ }^{8}$ This study showed that many strokes can be predicted and that relatively simple measures such as blood pressure control could reduce the burden of disease. It can be modified with generic medications and it can also be modified at the community level by implementing such policies as those aimed at reducing salt intake, losing weight and encouraging exercise. Systemic hypertension was observed to be the most significant $(\mathrm{p}=0.0001)$ risk factor for stroke in the present study (OR=6.12; 95\% CI; 3.70-10.812).

In the Interstroke Study. ${ }^{8}$, history of hypertension was a significant risk factor for all strokes $(\mathrm{OR}=2.64,99 \% \mathrm{CI}, 2.26$ 3.08; PAR 34.6\%, 99\% CI, 18.8-36.6) [Martin et al]. ${ }^{19}$ Similarly, the estimated 10-year risk of stroke in the elderly population of Spain was $19.6 \%$; the risk was more in hypertensive patients $(23.7 \%$; SD 18.5$)$ than in patients with high blood pressure without known hypertension (12.4\%; SD 9.2) or in normotensive subjects (5.3\%; SD $0.2 ; \mathrm{p}<0.01$ ) [Redon et al]. ${ }^{20}$ Likewise, for each $10 \mathrm{~mm}$ rise in systolic and diastolic blood pressure higher relative risks of total stroke were noted in Asian group than in Whites (1.2-1.3 and 1.2-1.5, respectively). The population attributable risk of hypertension to stroke was higher in Asians (i.e. $31 \%$ for ischaemic and $42 \%$ for haemorrhagic stroke) than in Whites (25\% and $34 \%$ respectively) [Zhang et al]. ${ }^{21}$ Conen and Bamberg. ${ }^{22}$ made a meta-analysis, which included 9,299 participants with 11.1 years of follow-up and 881 cardiovascular events.

They found a consistent association between mean $24 \mathrm{hr}$. systolic blood pressure and cardiovascular mortality and morbidity. Ambulatory Blood Pressure Monitoring (ABPM) was a strong predictor of stroke than other cardiovascular events, such as cardiovascular and total mortality. For each 10 $\mathrm{mm}$ rise of $24 \mathrm{hr}$. SBP, there was a hazard ratio (95\% confidence interval) of 1.33 (1.22-1.44) for stroke, 1.19 (1.131.26) for cardiovascular mortality, 1.12 (1.07-1.17) for total mortality and 1.17 (1.09-1.25) for cardiac endpoints. In their meta-analysis, daytime and night time blood pressure have a similar ability to predict cardiovascular events including stroke, however higher night time blood pressure was associated with increased total as well as cardiovascular mortality. The results of their meta-analysis are confirmed by recent data from the IDACO Study (International Database on Ambulatory Blood Pressure in relation to Cardiovascular Outcomes), which shows that $24 \mathrm{hr}$. systolic blood pressure was a strong predictor of stroke than cardiac events and cardiovascular mortality. ${ }^{23}$

Age and male sex are important non-modifiable risk factors for stroke. The mean age of cases in this study was $51.30 \pm 11.13$ years and $51.93 \pm 14.60$. Our present study shows that most patients were above 60 years of age $(n=82,52.56 \%)$ and male preponderance was observed in stroke. Studies performed on ischaemic stroke among the 15-45 years' age group from India also reported a male preponderance. 24 
Similar findings have been reported from Denmark in cases of thromboembolic stroke. 25

Presence of CHD was a significant risk factor in cases in the present study $(\mathrm{p}<0.001, \quad \mathrm{OR}=2.33,95 \% \mathrm{CI}, 1.46-3.71)$. Similarly, in a large population based study, CAD was a significant risk factor for stroke [Boysen et al].26 In their study of classic risk factors, Rodgers A et al 27 noted a hazard ratio of 1.55 (95\% CI, 1.19-2.03) for CHD. Many risk factors (hypertension, diabetes mellitus, dyslipidaemia, lack of exercise) are frequent in both CHD and stroke. Further, atherosclerosis, an invariable pathogenic process in CHD is also a common pathophysiologic mechanism in stroke. Thus, common risk factors and common pathogenesis are probably responsible for the increased risk of stroke in patients with CHD.

\section{CONCLUSION}

To conclude in the present hospital-based case control study, systemic hypertension $(\mathrm{p}<0.001)$ and coronary heart diseases were significant risk factors in patients with stroke. The future burden of stroke is likely to increase in the developing countries because of fast changing life styles and population restructuring. Risk factor assessment is an important step towards better understanding of pathogenesis, treatment and prevention of stroke.

\section{RECOMMENDATIONS}

There should be a proper health education and increase in awareness about the primordial prevention of risk factors, which leads to increase in stroke morbidity and mortality. Periodic screening of some diseases which are indirectly linked with stroke like hypertension, diabetes mellitus, dyslipidaemia, heart diseases, etc., should also be undertaken and proper preventive strategies should be applied if needed. People should be motivated and encouraged to undergo regular physical exercises and to avoid sedentary life-styles. Life style modification and non-pharmacological as well as pharmacological interventions for the modifiable risk factors should form an integral aspect of patient care.

\section{LIMITATION OF THE STUDY}

There are some limitations in our study. Apart from inadequate numbers (In spite of including three months' record), not all the patients underwent all the investigations, thereby making analysis and interpretation difficult. Being a tertiary care centre, the referred patient's profiles may not be representative, creating a bias. Because of paucity of information, this study gives an idea to undertake more detailed studies with bigger sample sizes to explore the associations and risk factors

\section{STRENGTH OF THE STUDY}

Our present study is a step towards determination of risk factors of stroke. Data regarding prevalence of stroke and its risk factors in Bihar is very scanty, as there has been no study yet conducted in this part of India. The study was well needed here, as no study has been conducted on stroke especially in Kishanganj.

\section{REFERENCES}

1. World Health Organization. Steps stroke manual. www.who.int/chp/steps/stroke. Accessed 23rd October 2009.

2. Lozano R, Naghavi M, Foreman $K$, et al. Global and regional mortality from 235 causes of death for 20 age groups in 1990 and 2010: a systemic analysis for the local burden of disease study 2010. Lancet 2012;380(9859):2095-128.

3. Murray CJ, Vos T, Lozano R, et al. Disability adjusted life year (DALYs) for 291 diseases and injuries in 21 regions, 1990-2010: a systematic analysis for the global burden of disease study 2010. Lancet 2012;380(9859):2197223.

4. Bonita R, Mendis S, Truelsen T, et al. The global stroke initiative. Lancet Neurol 2004;3(7):391-3.

5. Towfighi A, Saver JL. Stroke declines from third to fourth leading cause of death in United States: historical perspective and challenges ahead. Stroke 2011;42(8):2351-5.

6. Kissela BM, Khoury JC, Alwell K, et al. Age at stroke: temporal trends in stroke incidence in large, biracial population. Neurology 2012;79(17):1781-7.

7. Johnston SC, Mendis S, Mathers CD. Global variation in stroke burden and mortality estimates from monitoring, surveillance and modelling. Lancet Neurol 2009;8(4):345-54.

8. Martin J O'Donnell, Denis Xavier, Lisheng Liu, et al. Risk factors for ischaemic and intracerebral haemorrhagic stroke in 22 countries (the INTERSTROKE STUDY): a cross-control study. Lancent 2010;376(9735):112-23.

9. Arnold M, Halpern M, Meier N, et al. Age dependent differences in demographics, risk-factors, co-morbidity, aetiology, management and clinical outcome of acute ischaemic stroke. J Neurol 2008;255(10):1503-7.

10. Mehindiratta MM, Agarwal P, Sen K, et al. Stroke in young adults: a study from a university hospital in north India. Med Sci Monit 2004;10(9):CR535-41.

11. Jamrozik K, Broadhurst RJ, Anderson CS, et al. The role of life-style factors in the aetiology of stroke: a population based case-control study in Perth, western Australia. Stroke 1994;25(1):51-9.

12. WHOINDIA. Org. Assessment of burden of noncommunicable diseases in India. Final report of project WR/SE IND RPC 001 RB 02. SE/02/419575. New Delhi: Indian council of medical research; 2004. Available from: http://www.whoindia.org/link Files/Assessment of burden of NCD hypertension. Assessment of burden of NCDs. Pdf. Last assessed on Aug 27, 2009.

13. Gupta R. Trends in hypertension epidemiology in India. J Hum Hypertension 2004;18(2):73-8.

14. Teunissen LL, Rinkle GJE, Algra A, et al. Risk factors for subarachnoid haemorrhage: a systemic review. Stroke 1996;27:544-9.

15. Lipska K, Sylaja PN, Sarma PS, et al. Risk factors for acute ischaemic stroke in young adults in south India. J Neurol Neurosurg Psychiatry 2007;78(9):959-63.

16. Neaton JD, Wentworth DN, Cutler J, et al. Risk factors for death from different types of stroke. Multiple risk factor intervention trial research group. Ann Epidemiol 1993;3(5):493-9. 
17. Haapaniemi H, Hillbom M, Juvela S. Life style associated risk factors for acute brain infarction among persons of working age. Stroke 1997;28(1):26-30.

18. Avolio AP, Chen SG, Wang RP, et al. Effects of aging on changing arterial compliance and left ventricular load in a northern chinese urban community. Circulation 1983;68(1):50-8.

19. Martin LR, Friedman HS, Schwartz JE. Personality and mortality risk across the life span: the importance of conscientiousness as a biopsychosocial attributes. Health Psychology 2007;26(4):428-36.

20. Redon J, Cea-Calvo L, Lozano JV, et al. Differences in blood pressure control and stroke mortality across spain: the prevencion de riesgo de ictus (PREV-ICTUS) study. Hypertension 2007;49(4):799-805.

21. Zhang H, Thijs L, Staessen JA. Blood pressure lowering for primary and secondary prevention of stroke. Hypertension 2006;48:187-95.

22. Conen D, Bamberg F. Noninvasive $24 \mathrm{hr}$ ambulatory blood pressure and cardiovascular disease: a systematic review and meta-analysis. J Hypertens 2008;26(7):12909.
23. Boggia J, Thijs L, Li Y, et al. Risk stratification by $24 \mathrm{hr}$ ambulatory blood pressure and estimated glomerular filtration rate in 5322 subjects from 11 populations. Hypertension 2013;61(1):18-26.

24. Nayak SD, Nair M, Radhakrishnan K, et al. Ischaemic stroke in the young adult: clinical features, risk factors and outcome. Natl Med J India 1997;10(3):107-12.

25. Lidegard $O$, Soe $M$, Anderson NM. Cerebral thromboembolism among young women and men from Denmark, 1997-1982. Stroke 1986;17:670-5.

26. Boysen G, Krarup LH, Janjua H, et al. Validity of stroke diagnosis in a national register of patients. Neuroepidemiol 2007;28(3):150-4.

27. Rodger A, Lawes CM, Vander Hoorn S. International society of hypertension. Global burden of blood pressure related disease, 2001. Lancet 2008;371(9623):1513-8. 